\title{
Comparative study of clinicopathological significance, BIRC7, and STC2 expression between squamous cell/adenosquamous carcinomas and adenocarcinoma of gallbladder
}

\author{
Y. YUAN ${ }^{1,2}$, Z. L. YANG ${ }^{2, *}$, Q. ZOU ${ }^{1,2}$, J. H. LI ${ }^{3}$, D. Q. LI $^{4}$, L. F. LIANG ${ }^{5}$, G. X. ZENG ${ }^{6}$, S. L. CHEN ${ }^{7}$ \\ ${ }^{1}$ Department of Pathology, Third Xiangya Hospital, Central South University, Changsha, Hunan ,PR China; ${ }^{2}$ Research Laboratory of Hepato- \\ biliary Diseases, Second Xiangya Hospital, Central South University, Changsha, Hunan, PR China; ${ }^{3}$ Department of Pathology, Basic School of \\ Medicine, Central South University, Changsha, Hunan, PR China; ${ }^{4}$ Department of Pathology, Second Xiangya Hospital, Central South University, \\ Changsha, Hunan, PR China; ${ }^{5}$ Department of Hepatobiliary and Pancreatic Surgery, Hunan Provincial People's Hospital, Changsha, Hunan, \\ PR China; ${ }^{6}$ Department of Pathology, Loudi Central Hospital, Loudi, Hunan, PR China; ${ }^{7}$ Department of Pathology, Hunan Provincial Tumor \\ Hospital, Changsha, Hunan, PR China
}

${ }^{*}$ Correspondence: yangzhulin8@sina.com

Received December 20, 2012 / Accepted April 18, 2013

Gallbladder cancers (GBCs) are uncommon, but highly aggressive cancers. The majority of GBCs are adenocarcinomas (ACs), but rare subtypes of GBCs such as squamous cell carcinoma (SC) and adenosquamous carcinoma (ASC) are observed as well. The clinicopathological characteristics of SC/ASC have not been well documented. Expressions of BIRC7 and STC2 were observed in some tumors. However, BIRC7 and STC2 expressions and clinical significances in gallbladder cancer have not been reported.

In this study, the protein expressions of BIRC7 and STC2 in 46 SCs/ASCs and 80 ACs were measured using immunohistochemistry.

We demonstrated that positive BIRC7 and STC2 expressions were significantly associated with large tumor mass $(>3 \mathrm{~cm})$, high TNM stage and lymph node metastasis in SC/ASC and AC $(p<0.05)$. Positive expression of BIRC7 was significantly associated with invasion of around tissues and organs in both SC/ASC and AC. Additionally, negative BIRC7 and STC2 expressions were significantly associated with surgical curability in AC. Univariate Kaplan-Meier analysis showed that BIRC7 and STC2 expressions, differentiation, tumor size, TNM stages, invasion, lymph node metastasis, and surgical curability were significantly associated with post-operative survival in both SC/ASC and AC patients $(p<0.001)$. Multivariate Cox regression analysis showed that positive BIRC7 and STC2 expressions are independent poor-prognostic factors in both SC/ASC and AC patients.

Our study suggested that positive BIRC7 and STC2 expressions are closely correlated with clinical, pathological, and biological behaviors as well as poor-prognosis of gallbladder cancer.

Key words: gallbladder cancer, squamous cell carcinoma, adenosquamous carcinomas, BIRC7, STC2

Gallbladder cancers (GBCs) are relatively uncommon cancers, but the incidence is alarmingly increasing worldwide [1]. A majority of GBCs are adenocarcinomas (AC, 90-95\%) [2]; however, squamous cell carcinomas (SCs) and adenosquamous carcinomas (ASCs) are rarely encountered in the clinic, and are represented as individual case reports or analysis of small case series [3,4]. Early diagnosis of GBC is generally impossible because there are no noticeable or detectable signs or symptoms for GBC. Therefore, GBCs are frequently diagnosed at an advanced stage. At present, cholecystectomy is the only viable therapy for early stage GBCs $[5,6]$. Particularly, the therapeutic interventions for SCs/ASCs have not been well defined though curative resection at early stages can improve prognosis [7]. Postoperative adjuvant therapy, such as chemotherapy and radiation therapy, had no effect on the prognosis of ACs and SCs/ASCs[3]. Although some molecular markers have been identified to be associated with the tumorogenesis and prognosis of $\mathrm{AC}[8]$, no biomarkers have been identified in SC/ASC, particularly a comparative study of molecular markers between AC and SC/ASC has not been reported. 
Human baculoviral IAP repeat-containing 7 (BIRC7) is also known as activin, which is the inhibitor of some members of apoptotic protein family, containing a single baculovirus IAP repeat-containing 7 and a ring finger zinc binding domain, of which, BIR area is necessary to inhibit apoptotic activity induced by caspases, and ring finger zinc binding domain sometimes only increases anti-apoptotic activity but does not inhibit apoptosis [9-12]. The BIRC7 expression level is closely related to the occurrence, progress, clinical biological behaviors and prognosis of some malignant tumors, and that the cases with high expression of BIRC7 have poorer prognosis [13-20]. Recent studies have found that the positive expression rate of BIRC7 in gastric cancer cases with poor differentiation and lymph node metastasis is significantly higher than that in cases with well-differentiation and without lymph node metastasis, and the expressions in adjacent tissue and benign gastric mucosal lesions are negative [13]; in addition, Sun JG, Wagener N, Ye L et al. have found similar results in lung cancer [14], renal cell carcinoma [15], prostate cancer [16], non-Hodgkin lymphoma [17], nasopharyngeal carcinoma [18], esophageal cancer [19] and neuroblastoma[20] . In short, the positive expression of BIRC7 indicates higher malignancy, easy metastasis, strong invasive potential and poor prognosis. And the overexpression of BIRC7 renders malignant cells resistant to chemotherapy, so the inhibitors of BRIC7 are considered as potential adjuncts to chemotherapy in the treatment of malignant tumors [21]. Others' reports also showed antisense oligonucleotides or small interfering RNA (siRNA) targeting BIRC7 gene could reduce its expression, decrease viability and colony formation, induce apoptosis and enhance chemosensitivity of tumor cells $[22,23]$.

Stanniocalcin (STC) was first found in teleost, and later found in human and other mammals, which has been named as STC1 and STC2 [24-26]. STC2 is a glycoprotein hormone, widely expressed in many tissues of human, and might have autocrine or paracrine function. STC2 can adjust the metabolism balance of calcium and phosphorus, with the inhibitory activity on the promoter of sodium phosphate cotransporter; some studies have found that when there is dysfunction of endoplasmic reticulum, it could induce STC2 expression through pERK-ATF4 pathway; in addition, under oxidative stress and hypoxia, it could induce STC2 expression mediated by HIF1, without relying on pERK-ATF4 pathway [24-26] .Recent studies have found that STC2 is a powerful marker of poor prognosis in gastric cancer [27], colorectal cancer [28], prostate cancer [29], breast cancer [30], and other malignant tumors. These studies showed STC2 expression is closely related to the occurrence, progress, clinical biological behaviors and prognosis of these malignant tumors. In addition, Kita Y , Law AY et al have confirmed that STC2 is the marker of lymph node metastasis in esophageal squamous cell carcinoma [31] , and promote EMT(epithelial- mesenchymal transition) of ovarian cancer cells in hypoxic environment [32] .

Studies on the expression of BIRC7 and STC2 in gallbladder SC/ASC and AC tissues have not been reported. In this study, the expression levels of BIRC7 and STC2 in 46 SC/ASC cases and $80 \mathrm{AC}$ cases were studied by EnVision immunohistochemical method. The correlations of BIRC7 and STC2 expressions with clinicopathological characteristics and prognosis of $\mathrm{AC}$ and SC/ASC were comparatively evaluated.

\section{Material and methods}

Case selection. This study was pre-approved by The Ethics Committee for Human Research, Central South University. A total of 46 squamous cell/adenosquamous carcinoma (SC/ ASC) cases that underwent surgical resection or biopsy were diagnosed from a total of 1060 gallbladder cancer samples collected from January 1995 to December 2009 from 7 hospitals. Among the 1060 gallbladder cancers, 80 adenocarcinoma (AC) samples with available survival information were randomly selected for comparison in this study. Among the 46 SC/ASC patients, 27 patients were female and 19 were male $(\mathrm{F} / \mathrm{M}=$ $1.42)$ with an age variation from 35 to $82(55.8 \pm 9.6)$ years. Among the $80 \mathrm{AC}$ patients, 54 were female and 26 were male $(\mathrm{F} / \mathrm{M}=2.08)$ with an age variation from 33 to $80(53.8 \pm 9.9)$ years. Surgery included radical resection for 14 SCs/ASCs and 26 ACs, palliative surgery for 18 SCs/ASCs and 28 ACs, and no operation for 14 SCs/ASCs and 26 ACs with only biopsy. Survival information of all $46 \mathrm{SC} / \mathrm{ASC}$ and $80 \mathrm{AC}$ patients was obtained through letters and phone calls. The follow-up time was 2 years. Cases that survived longer than 2 years were included in the analysis as censored cases.

Immunohistochemistry staining. Four-micrometerthick sections were cut from routinely paraffin-embedded tissues of AC and SC/ASC. Staining was conducted with the ready-to-use, peroxidase-based EnVision ${ }^{\mathrm{nt}}$ Detection kit (Dako Laboratories, CA, USA) by following the user manual. The rabbit anti-BIRC7 and rabbit anti-STC2 antibodies were purchased from Abgent Company (Califorina, USA). BIRC7 and STC2 positive cells exhibited yellow-brown cytoplasmic staining. The positive control was a positive breast cancer tissues provided by Beijing Zhongshan Biotechnology Company (Beijing, China), while the negative control was created by replacing the primary antibody with $5 \%$ fetal bovine serum. From these sections we assessed 400 tumor cells by semi-quantitative measurements performed in 10 random high power fields, taking into account the number of positively stained and intensity of staining. Cases with positive cells $\geq 25 \%$ were considered positive, while cases with positive cells $<25 \%$ were considered negative [33-34]. All relative scores were accessed by two pathologists independently.

Statistical analysis. Data were analyzed using the statistical package for the Social Sciences Version 13.0 (SPSS 13.0).The inter-relationship of BIRC7 and STC2 expressions with histology or clinical factors were analyzed using $\chi 2$ or Fisher's exact test.Kaplan-Meier and time series test (log-rank test) were used for univariate survival analysis. Cox proportional hazards model was used for multivariate analysis and to determine the 95\% confidence interval. 


\section{Results}

Comparison of clinicopathological characteristics with BIRC7 and STC2 expression in SC/ASC and AC. The percentage of cases with age older than 45 years and tumor mass $>3 \mathrm{~cm}$ was significantly higher in SCs/ASCs than in ACs $(p<0.05)$. Whereas, the percentage of cases with poorly-differentiated tumor was significantly lower in SCs/ASCs than in ACs. No significant differences in other clinicopathological characteristics, such as sex, TNM stage, invasion, lymph node metastasis, history of gallstones, operative procedure, and average survival time were observed between SCs/ASCs and ACs. EnVision immunohistochemistry revealed that $\mathrm{BIRC} 7$ and STC2 positive reaction was mainly localized in the cytoplasm of SC/ASC and AC (Fig. 1). However, the percentage of positive BIRC7 and STC2 expression showed no significant differences between SC/ ASC and AC patients.

The association of BIRC7 and STC2 expression with clinicopathological characteristics of SC/ASC and AC. As shown in Table1, the percentage of positive BIRC7 and STC2 expression in tumor tissues was significantly higher in SCs/ ASCs with large tumor mass, higher TMN stage and lymph node metastasis than that in cases with small tumor mass, lower TMN stage and no lymph metastasis $(p<0.05$ or $p<0.01)$; the percentage of positive BIRC7 expression is significantly lower in invasion of peripheral tissues and organs than that in no-invasion of peripheral tissues and organs $(p<0.01)$; BIRC7 and STC2 expressions have no significant difference on gender, age and pathological type, differentiation, gallstone and surgical approach $(p>0.05)$.

As shown in Table2, the percentage of positive BIRC7 and STC2 expression in AC tumors was significantly higher in the cases with larger tumor mass, higher TMN stage with lymph node metastasis, invasion to the gallbladder surrounding tissues organs and radical resection than in cases with small tumor mass, lower TMN stage, no lymph metastasis, no invasion and only biopsy $(p<0.05, p<0.01$, or $p<0.001)$. BIRC7 and STC2 exhibited no significant association with sex or age, differentiation, and history of gallstones $(p>0.05)$.
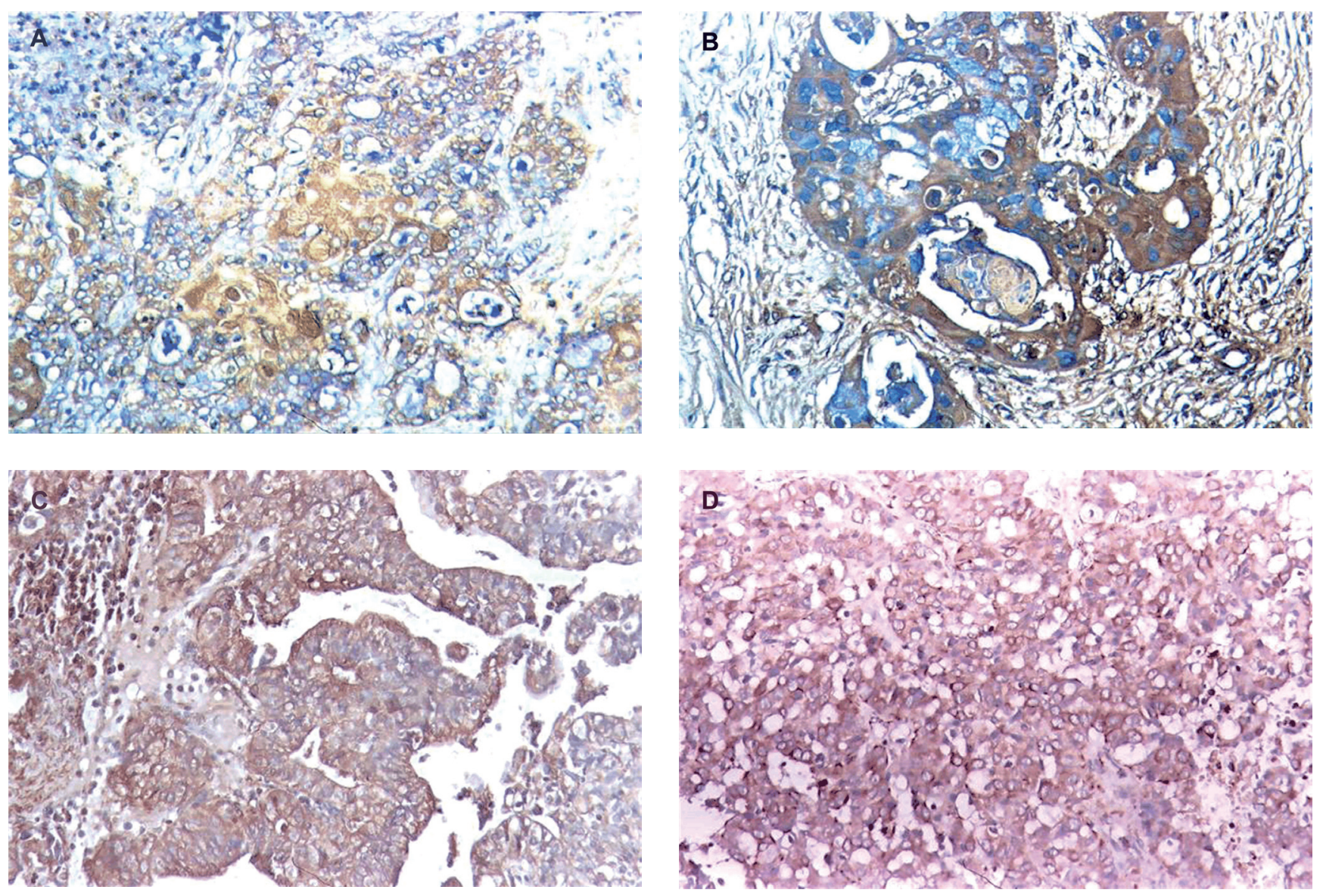

Figure 1. BIRC7 and STC2 expression in both SC/ASC and AC. EnVision immunohistochemistry, original magnification x200. BIRC7 and STC2 positive reaction was mainly localized in the cytoplasm. A, Positive BIRC7 expression in poorly differentiated squamous/adenosquamous carcinomas. B, Positive STC2 expression in moderately differentiated squamous/adenosquamous carcinomas. C, Positive BIRC7 expression in moderately differentiated adenocarcinomas. D, Positive STC2 expression in poorly differentiated adenocarcinomas. 
Table 1. The association of BIRC7 and STC2 expression with the clinicopathological characteristics of SC/ASC

\begin{tabular}{|c|c|c|c|c|c|c|c|}
\hline \multirow{2}{*}{$\begin{array}{l}\text { clinicopathological } \\
\text { characteristic }\end{array}$} & \multirow{2}{*}{ Total No: } & \multicolumn{3}{|c|}{ BIRC7 } & \multicolumn{2}{|c|}{ STC2 } & \multirow[b]{2}{*}{$P$} \\
\hline & & Pos No: (\%) & $\chi^{2}$ & $P$ & Pos No: (\%) & $\chi^{2}$ & \\
\hline \multicolumn{8}{|l|}{$\operatorname{sex}$} \\
\hline male & 19 & $12(63.2)$ & 0.266 & 0.606 & $7(36.8)$ & 2.242 & 0.134 \\
\hline female & 27 & $15(55.6)$ & & & $16(59.3)$ & & \\
\hline \multicolumn{8}{|l|}{ age(year) } \\
\hline$\leq 45$ & 3 & $1(33.3)$ & 0.852 & 0.356 & $0(0.0)$ & 3.209 & 0.073 \\
\hline$>45$ & 43 & $26(60.5)$ & & & $23(53.5)$ & & \\
\hline \multicolumn{8}{|l|}{ pathologic types } \\
\hline SC & 26 & $18(69.2)$ & 2.738 & 0.098 & $15(57.7)$ & 1.415 & 0.234 \\
\hline ASC & 20 & $9(45.0)$ & & & $8(40.0)$ & & \\
\hline \multicolumn{8}{|l|}{ differentiation } \\
\hline well & 16 & $8(50.0)$ & & & $5(31.3)$ & & \\
\hline moderately & 24 & $14(58.3)$ & 2.003 & 0.367 & $14(58.3)$ & 3.583 & 0.167 \\
\hline poorly & 6 & $5(83.3)$ & & & $14(66.7)$ & & \\
\hline \multicolumn{8}{|l|}{ tumor diameter $(\mathrm{cm})$} \\
\hline$\leq 3 \mathrm{~cm}$ & 20 & $8(40.0)$ & 5.101 & 0.024 & $6(30.0)$ & 5.662 & 0.019 \\
\hline$>3$ & 26 & $19(69.2)$ & & & $17(65.4)$ & & \\
\hline \multicolumn{8}{|l|}{ cholecystolithiasis } \\
\hline No & 18 & $10(55.6)$ & 0.120 & 0.729 & $9(50.0)$ & 0.000 & 1.000 \\
\hline Yes & 28 & $17(60.7)$ & & & $14(50.0)$ & & \\
\hline \multicolumn{8}{|l|}{ TNM stages } \\
\hline $\mathrm{I}+\mathrm{II}$ & 12 & $3(25.0)$ & & & $3(25.0)$ & & \\
\hline III & 20 & $12(60.0)$ & 9.849 & 0.007 & $9(45.0)$ & 7.769 & 0.020 \\
\hline IV & 14 & $12(85.7)$ & & & $11(78.6)$ & & \\
\hline \multicolumn{8}{|l|}{ lymph node metastasis } \\
\hline no & 17 & $6(35.3)$ & 6.091 & 0.014 & $5(29.4)$ & 4.572 & 0.032 \\
\hline yes & 29 & $21(72.4)$ & & & $18(62.1)$ & & \\
\hline \multicolumn{8}{|l|}{ regional invasion } \\
\hline no & 16 & $5(31.3)$ & 7.623 & 0.006 & $5(31.3)$ & 3.450 & 0.063 \\
\hline yes & 30 & $22(73.3)$ & & & $18(60.0)$ & & \\
\hline \multicolumn{8}{|l|}{ surgical methods } \\
\hline radical & 14 & $5(35.7)$ & & & $4(28.6)$ & & \\
\hline palliative & 18 & $11(61.1)$ & 5.374 & 0.068 & $10(55.6)$ & 3.937 & 0.140 \\
\hline without resection & 14 & $11(78.6)$ & & & $9(64.3)$ & & \\
\hline
\end{tabular}

The correlation between BIRC7 and/or STC2 expression with survival in patients with SC/ASC and AC. Survival information of 46 SC/ASC patients was obtained through letters and phone calls. The follow-up time was 2 years and patients that survived longer than 2 years were included in analysis as censored cases. 13 patients survived over 1 year $(4$ cases survived longer than 2 years) and 33 patients survived less than 1 year with an average survival time of $10.07 \pm 0.78$ months. The Kaplan-Meier survival analysis revealed that differentiation, tumor size, TNM stage, lymph node metastasis, invasion and surgical approach $(p<0.001)$ were significantly associated with average survival time in the SC/ASC patients. The average survival time of BIRC7 and STC2 positive patients [8.04(4-24); 7.61(4-12)] was significantly lower than that of BIRC7 and STC2 negative patients [13.32(6-24); 12.83(6-24)] ( $p=0.001$ ) (Fig. 2). Cox multivariate analysis showed that the tumor size $(\geq 3 \mathrm{~cm})$, TMN stage, invasion, surgical approach as well as BIRC7 or STC2-positive expression were negatively correlated with post-operative survival, and positively correlated with mortality, suggesting that $\mathrm{BIRC} 7(\mathrm{RR}=3.575, p=0.002)$ or STC2 $(\mathrm{RR}=2.492, p=0.038)$ positivity is a risk factor.

Survival information of $80 \mathrm{AC}$ patients was obtained through letters and phone calls. The follow-up time was 2 years and patients that survived longer than 2 years was included in analysis as censored cases. 23 patients survived over 1 year $(9$ cases survived longer than 2 years) and 57 patients survived less than 1 year with an average survival time of $10.34 \pm 0.63$ months. The Kaplan-Meier survival analysis revealed that differentiation, tumor size, TNM stage, lymph node metastasis, invasion, and surgical approach $(p<0.001)$ were significantly associated with average survival time of AC patients. The average survival time of BIRC7 and STC2 positive AC patients [8.09(3- 
Table 2 .The association of BIRC7 and STC2 expression with the clinicopathological characteristics of AC

\begin{tabular}{|c|c|c|c|c|c|c|c|}
\hline \multirow{2}{*}{$\begin{array}{l}\text { clinicopathological } \\
\text { characteristic }\end{array}$} & \multirow{2}{*}{ Total No. } & \multicolumn{3}{|c|}{ BIRC7 } & \multicolumn{3}{|c|}{ STC2 } \\
\hline & & Pos No: (\%) & $\chi^{2}$ & $P$ & Pos No: (\%) & $\chi^{2}$ & $P$ \\
\hline \multicolumn{8}{|l|}{ sex } \\
\hline male & 26 & $18(69.2)$ & 3.152 & 0.076 & $16(61.5)$ & 1.262 & 0.0 .261 \\
\hline female & 54 & $26(48.1)$ & & & $26(48.1)$ & & \\
\hline \multicolumn{8}{|l|}{ age (year) } \\
\hline$\leq 45$ & 16 & $8(50.0)$ & 0.202 & 0.653 & $6(37.5)$ & 1.805 & 0.074 \\
\hline$>45$ & 64 & $36(56.2)$ & & & $36(56.3)$ & & \\
\hline \multicolumn{8}{|l|}{ differentiation } \\
\hline well & 27 & $11(40.7)$ & & & $12(44.4)$ & & \\
\hline moderately & 25 & $13(52.0)$ & 5.362 & 0.068 & $12(48.0)$ & 2.465 & 0.292 \\
\hline poorly & 28 & $20(71.4)$ & & & $18(64.3)$ & & \\
\hline \multicolumn{8}{|l|}{ tumor diameter $(\mathrm{cm})$} \\
\hline$\leq 3 \mathrm{~cm}$ & 50 & $21(42.0)$ & 9.104 & 0.003 & $20(40.0)$ & 8.354 & 0.004 \\
\hline$>3$ & 30 & $23(76.7)$ & & & $22(73.3)$ & & \\
\hline \multicolumn{8}{|l|}{ cholecystolithiasi } \\
\hline No & 42 & $21(50.0)$ & 0.893 & 0.345 & $18(42.9)$ & 3.297 & 0.069 \\
\hline Yes & 38 & $23(60.5)$ & & & $24(63.2)$ & & \\
\hline \multicolumn{8}{|l|}{ TNM stages } \\
\hline $\mathrm{I}+\mathrm{II}$ & 21 & $5(23.8)$ & & & $8(38.1)$ & & \\
\hline III & 38 & $21(53.3)$ & 16.260 & 0.000 & $16(42.1)$ & 12.684 & 0.002 \\
\hline IV & 21 & $18(85.7)$ & & & $18(85.7)$ & & \\
\hline \multicolumn{8}{|l|}{ lymph node metastasis } \\
\hline No & 30 & $11(36.7)$ & 6.519 & 0.011 & $11(36.7)$ & 4.825 & 0.029 \\
\hline Yes & 50 & $33(66.0)$ & & & $31(62.0)$ & & \\
\hline \multicolumn{8}{|l|}{ regional invasion } \\
\hline No & 31 & $12(38.7)$ & 5.427 & 0.020 & $10(32.3)$ & 8.316 & 0.004 \\
\hline Yes & 49 & $32(65.3)$ & & & $32(65.3)$ & & \\
\hline \multicolumn{8}{|l|}{ surgical methods } \\
\hline radical & 26 & $9(34.6)$ & & & $8(30.8)$ & & \\
\hline palliative & 28 & $15(53.6)$ & 9.437 & 0.009 & $13(46.4)$ & 13.664 & 0.000 \\
\hline without resection & 26 & $20(76.98)$ & & & $21(80.8)$ & & \\
\hline
\end{tabular}

18); 8.31(3-24)] was significantly lower than that of BIRC7 and STC2 negative AC patients [13.97(6-24); 13.42(5-24)] $(p<0.001)$ (Fig. 2). Cox multivariate analysis showed that differentiation, tumor size $(\geq 3 \mathrm{~cm})$, TMN stage, lymph node metastasis, invasion, surgical approach as well as BIRC7 $(\mathrm{RR}=2.065, p=0.009)$ or STC2 $(\mathrm{RR}=2.085, p=0.018)$-positive expression were positively correlated with poor survival of AC patients .

\section{Discussion}

Articles on squamous cell/adenosquamous carcinomas (SCs/ASCs) of the gallbladder are highly limited in literature because of the rarity of these cancers. Until now, no molecular markers related to the malignancy, metastasis, invasion, and prognosis of SC/ASC have been identified. No study investigated the differences in molecular signature between the rare SC/ASC subtype and the major AC subtype of the gallbladder cancers (GBCs) due to the lack of SC/ASC samples. In this study, an extensive collection of SC/ASC samples made it possible to systemically compare the differences in clinicopathological and biological characteristics between the rare SC/ASC subtype and the relative common AC subtype of GBCs. Importantly, we found that BIRC7 and STC2 overexpressions were significantly associated with large tumor mass, high TNM stage, metastasis, invasion, and poor prognosis in both SC/ASC and AC patients. Our study highlighted the role of BIRC7 and STC2 overexpressions in the progression, clinical biological behaviors, and poor-prognosis of $\mathrm{AC}$ and SC/ASC tumors.

Previous studies have demonstrated that the expression level of BIRC7 is significantly up-regulated in colorectal cancer, and negative in normal colonic mucosa, and univariate survival analysis have shown that the expression level of BIRC7 is negatively correlated with survival time [35].The positive expression rate of BIRC7 in patients with advanced neuroblastoma is significantly higher than that in patients at early or intermediate stage [36]. In this studies, we observed that overexpressions of BIRC7, in both SC/ASC and AC, were 

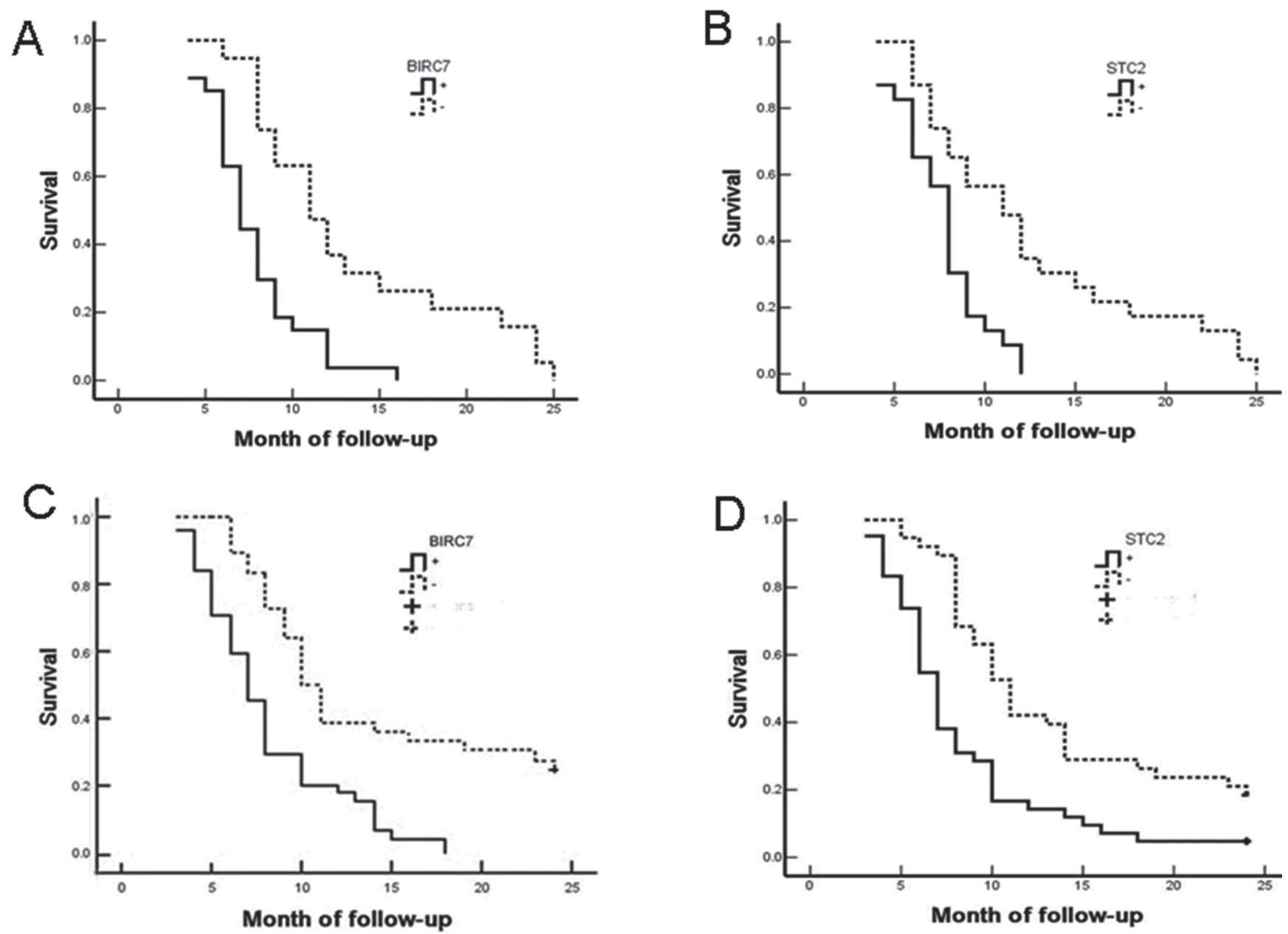

Figure 2. BIRC7 and STC2 expression and survival in patients with SC/ASC and AC. A, Kaplan-Meier plots of overall survival in patients with SC/ASC and with BIRC7 positive and negative expression. B, Kaplan-Meier plots of overall survival in patients with SC/ASC and with STC2 positive and negative expression. C, Kaplan-Meier plots of overall survival in patients with AC and with BIRC7 positive and negative expression. D, Kaplan-Meier plots of overall survival in patients with AC and with STC2 positive and negative expression.

significantly associated with large tumor size, high TNM stage, lymph node metastasis, invasion and poor survival.These results might suggest that BIRC7 is a tumor maker for reflecting the carcinogenesis, progression, biological behaviors and prognosis in both SC/ASC and AC of gallbladder.

The STC2 gene, located on chromosome 5q35.2, belongs to the STC family [37]. The STC family includes two genes, STC1 and STC2. It was reported the STC1 gene is associated with some cancers such as hepatocellular carcinoma and colorectal cancer [38]. Some Studies on STC2 gene expression relating to cancer been reported. In breast cancer, STC2 expression was found to be associated with tumor estrogen receptor (ER) status, high STC2 expression was associated with good prognosis in ER-posive breast cancer patients[39] . But it was reported that a significant high expression levels of STC2 in metastatic cases in 5 to 10 years postoperation compared with no-metastastic ones after 10 year postoperation [40]. We examined the relationships between STC2 expression and clinicopathological factors in both SC/ASC and AC of gallbladder, the overexpression of STC2 was associated with large tumor size, high TNM stage, lymph node metastasis, invasion and poor survival. The results suggested that the expression of STC2 might have important impact on carcinogenesis, progression, clinical behaviors and prognosis of gallbladder cancer.

Although most GBCs were found at an advanced stage, radical resection is the most efficient therapy. In our study, $73.8 \%$ of AC and $66.9 \%$ of SC/ASC were diagnosised with TNM III and IV stage tumor, with poor survival. Less half of the patients received the opportunity with radical resection surgery. Thus, new therapeutic approaches to improve patients' survival are necessary. And early diagnosis method is needed. As we found in this study, BIRC7 and STC2 are malignant makers in both AC and SC/ASC patients. This study identified BIRC7and STC2 were important gene makers as novel targets 
molecule for metastasis and invasion, and have been associated with cancer progression, prognosis in SC/ASC and AC . Thus, these characteristics give them high potential as specifically for targeted treatment of gallbladder carcinoma.

\section{References}

[1] HSING AW, GAO YT, HAN TQ, RASHID A, SAKODA LC et al.Gallstones and the risk of biliary tract cancer: a populationbased study in China. British J of Cancer. 2007; 97: 1577-82. http: //dx.doi.org/10.1038/sj.bjc.6604047

[2] OOTANI T, SHIRAI Y, TSUKADA K, MUTO T. Relationship between gallbladder carcinoma and the segmental type of adenomyomatosis of the gallbladder. Cancer 1992; 69: 2647-52. http://dx.doi.org/10.1002/1097-0142(19920601)69: 11<2647: : AID-CNCR2820691105>3.0.CO; 2-0

[3] JAUARAMANS, JARNAGIN WR. Management of gallbladder cancer. Gastroenterol Clin North Am. 2010; 39: 331-42. http: //dx.doi.org/10.1016/j.gtc.2010.02.006

[4] ROA JC, TAPIA O, CAKIR O, BASTURK O, DURSUN N et al. Squamous cell and adenosquamous carcinomas of the gallbladder: clinicopathological analysis of 34 cases identified in 606 carcinomas. Mod Pathol. 2011; 24: 1069-78. http: //dx.doi.org/10.1038/modpathol.2011.68

[5] REID KM, RAMOS-DE LA MEDINA A, DONOHUE JH.. Diagnosis and surgical management of gallbladder cancer: a review. J Gastrointest Surg .2007; 11: 671-81. http: //dx.doi. org/10.1007/s11605-006-0075-x

[6] DE ARETXABALA X, ROA I, BURGOS L, LOSADA H, ROA JC et al. Gallbladder cancer: an analysis of a series of 139 patients with restricted to the subserosal layer. J Gastrointest Surg .2006; 10: 186-92. http: //dx.doi.org/10.1016/j.gassur.2005.11.003

[7] PARK SB, KIM YH, RHO HL, CHAE GB, HONG SK.Primary carcinosarcoma of the gallbladder. J Korean Surg Soc. 2012; 82: 54-8. http: //dx.doi.org/10.4174/jkss.2012.82.1.54

[8] MAURYA SK, TEWARI M, MISHRA RR, SHUKLA HS. Genetic aberrations in gallbladder cancer. Surg Oncol. 2012; 21: 37-43. http: //dx.doi.org/10.1016/j.suronc.2010.09.003

[9] LIU B, HAN M, WEN JK, WANG L. Livin/ML-IAP as a new target cancer treatment.Cancer Lett. $2007 ; 250$ : 168-76. http: //dx.doi.org/10.1016/j.canlet.2006.09.024

[10] WANG L, ZHANG Q, LIU B, HAN M, SHAN B. Challenge and promise: roles for Livin in progression and therapy of cancer.Mol Cancer Ther. 2008 ; 12: 3661-9. http: //dx.doi. org/10.1158/1535-7163.MCT-08-0480

[11] AUGELLO C, CARUSO L, MAGGIONI M, DONADON M,MONTORSI M. Inhibitors of apoptosis proteins (IAPs) expression and their prognostic significance in hepatocellular carcinoma.BMC Cancer. 2009; 9: 125. http: //dx.doi. org/10.1186/1471-2407-9-125

[12] LIU HB, KONG CZ, ZENG Y, LIU XK, BI JB et al.Livin may serve as a marker for prognosis of bladder cancer relapse and a target of bladder cancer treatment.Urol Oncol. 2009; 27: 277-83. http: //dx.doi.org/10.1016/j.urolonc.2008.03.015

[13] WANG TS, DING QQ, GUO RH, SHEN H, SUN J et al. Expression of livin in gastric cancer and induction of apoptosis in SGC-7901 cells by shRNA-mediated silencing of livin
gene.Biomed Pharmacother. 2010; 64: 333-8. http: //dx.doi. org/10.1016/j.biopha.2009.06.002

[14] SUN JG, LIAO RX, ZHANG SX, DUAN YZ, ZHUO WL et al. Role of inhibitor of apoptosis protein Livin in radiation resistance in nonsmall cell lung cancer.Cancer Biother Radiopharm. 2011; 26: 585-92. http: //dx.doi.org/10.1089/cbr.2011.0962

[15] WAGENER N, CRNKOVIC-MERTENS I, VETTER C, MACHER-GOPPINGER S, BEDKE J et al.Expression of inhibitor of apoptosis protein Livin in renal cell carcinoma and non-tumorous adult kidney.Br J Cancer. 2007; 97: 1271-6. http: //dx.doi.org/10.1038/sj.bjc.6604028

[16] YE L, SONG X, LI S, YANG D, ZHANG J et al. Livin- $\alpha$ promotes cell proliferation by regulating G1-S cell cycle transition in prostate cancer.Prostate. 2011 Jan 1; 71(1): 42-51.http: //dx.doi.org/10.1002/pros.21220

[17] WU H, MA Y, ZHU Y, SHEN Y, GU C et al. Expression of BIRC7 protein and mRNA in non-Hodgkin's lymphoma.Leuk Lymphoma. 2006; 47: 1110-6. http: //dx.doi.org/10.1080/ $\underline{10428190500472271}$

[18] XIANG Y, YAO H, WANG S, HONG M, HE J et al. Prognostic value of Survivin and Livin in nasopharyngeal carcinoma. Laryngoscope. 2006; 116: 126-30. http://dx.doi.org/10.1097/ 01.mlg.0000187392.87904.35

[19] CHEN L, REN GS, LI F, SUN SQ. Expression of livin and vascular endothelial growth factor in different clinical stages of human esophageal carcinoma. World J Gastroenterol. 2008; 14: 5749-54. http: //dx.doi.org/10.3748/wjg.14.5749

[20] KIM DK, ALVARADO CS, ABRAMOWSKY CR, GU L, ZHOU M et al. Expression of inhibitor-of-apoptosis protein (IAP) livin by neuroblastoma cells: correlation with prognostic factors and outcome. Pediatr Dev Pathol. 2005; 8: 621-9. http: //dx.doi.org/10.1007/s10024-005-4108-3

[21] WANG R, LIN F, WANG X, GAO P, DONG K et al.Silencing Livin gene expression to inhibit proliferation and enhance chemosensitivity in tumor cells. Cancer Gene Ther. 2008; 15: 402-12. http: //dx.doi.org/10.1038/cgt.2008.16

[22] EL ALI Z, GRZYMISŁAWSKI M, MAJEWSKI P, BAUMANNANTCZAK A, KOSOWICZ J.Anti-livin antibodies: novel markers of malignant gastrointestinal cancers.Pol Arch Med Wewn. 2010; 120: 26-9.

[23] WANG X, XU J, JU S, NI H, ZHU J et al. Livin gene plays a role in drug resistance of colon cancer cell. Clin Biochem, 2010, 43: 655-660. http: //dx.doi.org/10.1016/j.clinbiochem. 2010.02.004

[24] YEUNG BH,LAW AY,WONG CK.Evolution and roles of stanniocalcin. Mol Cell Endocrinol. 2012; 349: 272-80. http: //dx.doi.org/10.1016/j.mce.2011.11.007

[25] DIMATTIA GE, VARGHESE R, WAGNER R, WAGNER GF. Molecular cloning and characterization of stanniocalcin-related protein.Mol Cell Endocrinol.1998 ; 146: 137-40. http: //dx.doi.org/10.1016/S0303-7207(98)00163-4

[26] VARGHESE R, WONG CK, DEOL H, WAGNER GF. Comparative analysis of mammalian stanniocalcin genes. Endocrinology. 1998; 139: 4714-25. http: //dx.doi.org/ 10.1210/en.139.11.4714

[27] YOKOBORI T, MIMORI K, ISHII H, IWATSUKI M, TANAKA $\mathrm{F}$ et al.Clinical significance of stanniocalcin 2 as 
a prognostic marker in gastric cancer.Ann Surg Oncol. 2010; 17: 2601-7. http: //dx.doi.org/10.1245/s10434-010-1086-0

[28] IETA K, TANAKA F, YOKOBORI T, KITA Y, HARAGUCHI $\mathrm{N}$ et al.Clinicopathological significance of stanniocalcin 2 gene expression in colorectal cancer.Int J Cancer. 2009; 125: 926-31. http: //dx.doi.org/10.1002/ijc.24453

[29] TAMURA K, FURIHATA M, CHUNG SY, UEMURA M, YOSHIOKA $\mathrm{H}$ et al.Stanniocalcin 2 overexpression in castration-resistant prostate cancer and aggressive prostate cancer. Cancer Sci. 2009; 100: 914-9. http: //dx.doi.org/10.1111/ j.1349-7006.2009.01117.x

[30] RAULICS, RAMOS-VALDES Y,DIMATTIA GE.Stanniocalcin 2 expression is regulated by hormone signalling and negatively affects breast cancer cell viability in vitro.J Endocrinol. 2008; 197: 517-29. http: //dx.doi.org/10.1677/JOE-08-0043

[31] KITA Y, MIMORI K, IWATSUKI M, YOKOBORI T, IETA K et al.STC2: a predictive marker for lymph node metastasis in esophageal squamous-cell carcinoma.Ann Surg Oncol. 2011; 18: 261-72. http: //dx.doi.org/10.1245/s10434-010-1271-1

[32] LAW AY, WONG CK. Stanniocalcin-2 promotes epithelialmesenchymal transition and invasiveness in hypoxic human ovarian cancer cells.Exp Cell Res. 2010; 316: 3425-34. http: //dx.doi.org/10.1016/j.yexcr.2010.06.026

[33] VIDA KHATAMIANFAR, FATMA VALIYEVA, PAULS RENNIE, WEI-YANG LU, BURTON B YANG et al. TRIM59, a novel multiple cancer biomarker for immunohistochemical detection of tumorigenesis. BMJ Open. $2012: 2$ : 1410.

[34] SANADA Y, YOSHIDA K, OHARA M, TSUTANI Y. Expression of orotate phosphori -bosyltransferase(OPRT) in hepatobiliary and pancreatic carcinoma.Pathol Oncol Res. 2007; 13: 105-13. http: //dx.doi.org/10.1007/BF02893485

[35] XI RC, BIAO WS, GANG ZZ. Significant elevation of survivin and livin expression in human colorectal cancer: inverse correlation between expression and overall survival.Onkologie. 2011; 34: 428-32. http: //dx.doi.org/10.1159/000331132

[36] DASQUPTA A, ALVARADO CS, XU Z, FINDLEY HW. Expression and functional role of inhibitor of apoptosis protein liviv (BRIRC7). Biochem Biophys Res Commun,2010; 400: 53-59. http: //dx.doi.org/10.1016/j.bbrc.2010.08.001

[37] WHITE KE, BIBER J, MURER H, ECONS MJ. Chromosomal localization of two human genes involved in phosphate homeostasis: the type IIb sodium-phosphate cotransporter and stanniocalcin-2. Somat Cell Mol Genet. 1998; 24: 357-62. http: //dx.doi.org/10.1023/A: 1024442524808

[38] FUJIWARA Y, SUGITA Y, NAKAMORI S, MIYAMOTO A, SHIOZAKI K et al. Assessment of Stanniocalcin-1 mRNA as a molecular marker for micrometastases of various human cancers. Int J Oncol. 2000; 16: 799-804.

[39] ESSEGHIR S, KENNEDY A, SEEDHAR P, NERURKAR A, POULSOM R et al. Identification of NTN4, TRA1, and STC2 as prognostic markers in breast cancer in a screen for signal sequence encoding proteins. Clin Cancer Res. 2007; 13: 3164-73. http: //dx.doi.org/10.1158/1078-0432.CCR-07$\underline{0224}$

[40] JOENSUU K, HEIKKILA P, ANDERSSON LC. Tumor dormancy: elevated expression of stanniocalcins in late relapsing breast cancer. Cancer Lett. 2008; 265: 76-83. http: //dx.doi. org/10.1016/j.canlet.2008.02.022 